\title{
Pressure and Temperature Effects on Stoichiometry and Microstructure of Nitrogen-Rich TiN Thin Films Synthesized via Reactive Magnetron DC-Sputtering
}

\author{
E. Penilla and J. Wang \\ Department of Mechanical Engineering, Bourns College of Engineering, University of California, Riverside, CA 92521, USA
}

Correspondence should be addressed to J. Wang, wang@engr.ucr.edu

Received 01 September 2007; Accepted 11 January 2008

Recommended by Jun Lou

\begin{abstract}
Nitrogen-rich titanium nitride (TiN) thin films containing excess nitrogen up to 87.0 at.\% were produced on (100) Si substrates via the reactive magnetron DC-sputtering of a commercially available 99.995 at.\% pure Ti target within an argon-nitrogen (Ar$\left.\mathrm{N}_{2}\right)$ atmosphere with a 20-to-1 gas ratio. The process pressure $\left(P_{P}\right)$ and substrate temperature $\left(T_{S}\right)$ at which deposition occurred were varied systematically between $0.26 \mathrm{~Pa}-1.60 \mathrm{~Pa}$ and between $15.0^{\circ} \mathrm{C}-600^{\circ} \mathrm{C}$, respectively, and their effects on the chemical composition, surface morphology, and preferred orientation were characterized by energy dispersive X-ray spectroscopy (EDS), field emission scanning electron microscopy (FE-SEM), and X-ray diffraction (XRD). The EDS analysis confirms increasing nitrogen content with increasing $P_{P}$ and $T_{S}$. The SEM images reveal a uniform and crystallized surface morphology as well as a closely packed cross-sectional morphology for all crystalline films and a loosely packed cross-sectional morphology for amorphous films. Films produced at lower $P_{P}$ and $T_{S}$ have a pyramidal surface morphology which transitions to a columnar and stratified structure as $P_{P}$ and $T_{S}$ increase. The XRD analysis confirms the existence of only the $\delta$-TiN phase and the absence of other nitrides, oxides, and/or sillicides in all cases. It also indicates that at lower $P_{P}$ and $T_{S}$, the preferred orientation relative to the substrate is along the (111) planes, and that it transitions to a random orientation along the (200), (220), and (311) planes as $P_{P}$ and $T_{S}$ increase and these results correlate with and qualify those observed by SEM.
\end{abstract}

Copyright (C) 2008 E. Penilla and J. Wang. This is an open access article distributed under the Creative Commons Attribution License, which permits unrestricted use, distribution, and reproduction in any medium, provided the original work is properly cited.

\section{INTRODUCTION}

Various transition metal nitrides such as TiN thin films have attracted considerable attention from researchers spanning the spectrum of the physical sciences. This is a testament to the myriad of potential applications that the TiN system affords because of its unique properties. They have been used as wear-resistant coatings on high-speed cutting tools [1-3], as infrared filtering coatings on windows [4], and as inexpensive decorative coatings on pens, watch dials, and so on [5] because of their golden luster. TiN thin films have also been used as microelectronic contacts [6], resistors [7], and, because of their high-chemical stability, as diffusion barriers $[8,9]$ between interconnects of microchips. A most recent application makes use of their biocompatibility and hemocompatability $[10,11]$, as they have been integrated as surface layers within orthopedic prostheses and cardiac valves $[12,13]$.
TiN thin films have been produced by various techniques, all derivatives of those used in semiconductor processing, such as electroplating [14], laser ablation [15, 16], chemical vapor deposition (CVD) [17], as well as the physical vapor deposition (PVD) techniques of evaporation and sputtering, reactive or otherwise [18-22]. Much of the problem associated with their production has been the need for high voltages and temperatures, which limit their integration within CMOS process flows. As of late, however, the commercial availability of TiN sputtering targets has facilitated their use within certain scenarios, where sputtering thin films is an option.

Although many practical applications, synthesis techniques, and deposition methods have been developed for TiN thin films, the literature seems to indicate that the basic metallurgy and physics of the TiN system are not completely understood $[1,23,24]$. The literature indicates that the first attempts to derive the TiN phase diagram were conducted 
by Wriedt and Murray as recently as 1987 , but the complete phase diagram covering the full compositional spectrum was not reported herein, namely, the data pertaining to overstoichiometric TiN was not reported [24]. Additional studies by Ristolainen et al. report the stability of TiN films with excess nitrogen contents up to 62 at. $\%$ via triode ion plating techniques [23]. Nonetheless, the limit of nitrogen solubility in TiN still appears uncertain as do the properties of such nitrogen-rich films as well as the effects of processing parameters on the basic metallurgy and physics.

All of the TiN films synthesized for this work, whose phase existence is confirmed by EDS and XRD analyses, have an excess nitrogen content of at least 70.4 at. $\%$ and up to 87 at.\% and it is believed that this is the first report of such produced films. This belief in tandem with the wide range of potential applicability within industry and academia prompted the authors' interest in characterizing some of the films' fundamental physics. Scanning electron microscopy was used to elucidate the surface and crosssectional characteristics, and SEM in concert with EDS and XRD was instrumental in determining the chemistry and crystallography.

\section{EXPERIMENTAL PROCEDURE}

\subsection{Preparation of TiN films}

TiN films with high nitrogen content were deposited onto polished (100) Si substrates with a native oxide layer and overall thicknesses of $480 \mu \mathrm{m}$ by sputtering a commercially developed 99.995 at.\% $\mathrm{Ti}$ target $(50.8 \mathrm{~mm}$ diameter $\times$ $6.35 \mathrm{~mm}$ thick) within an $\mathrm{Ar}-\mathrm{N}_{2}$ atmosphere. The target was mechanically clamped to a water-cooled direct-current magnetron cathode of an ultrahigh vacuum sputtering system (Orion 5 UHV sputtering system, AJA International, Inc., North Scituate, Mass, USA). The target must remain at a constant temperature throughout because the sputter yield and, as a consequence, the deposition rate are functions of target temperature [25]. Target poisoning also becomes an issue with the elevation of target temperature [25]. A DC-potential of $466 \mathrm{~V}$ was coupled to the cathode and this resulted in a driving current of $536 \mathrm{~mA}$ and a power dissipation of $250 \mathrm{~W}$. All depositions occurred at a target to substrate distance of $178 \mathrm{~mm}$ and lasted 6300 seconds.

The purity of the gases was 99.9995\% and the Ar- $\mathrm{N}_{2}$ ratio was 20 to 1 in all cases. Gas flow was controlled by 2 independently calibrated mass flow controllers (MFC) capable of delivering up to 20 SCCM of gas. The MFCs are integrated within a computer-controlled feedback loop to ensure constant flow and gas mixture throughout the entire deposition process. At full gas flow, $P_{P}$ was controlled by adjusting a three-position throttle valve, which is placed in series between the preparation chamber and a $500 \mathrm{~L}$ turbomechanical pump, allowing for the adjustment of conductance between the two. Films were synthesized with $P_{P}$ set points of $0.26 \mathrm{~Pa}, 0.53 \mathrm{~Pa}, 1.07 \mathrm{~Pa}$, and $1.60 \mathrm{~Pa}$.

Before sputtering, the substrates were subjected to a series of ultrasonicated chemical baths including acetone, isopropanol (IPA) and deionized (DI) water. They were



FIgURE 1: Effect of $P_{P}$ and $T_{S}$ variations on nitrogen solubility.

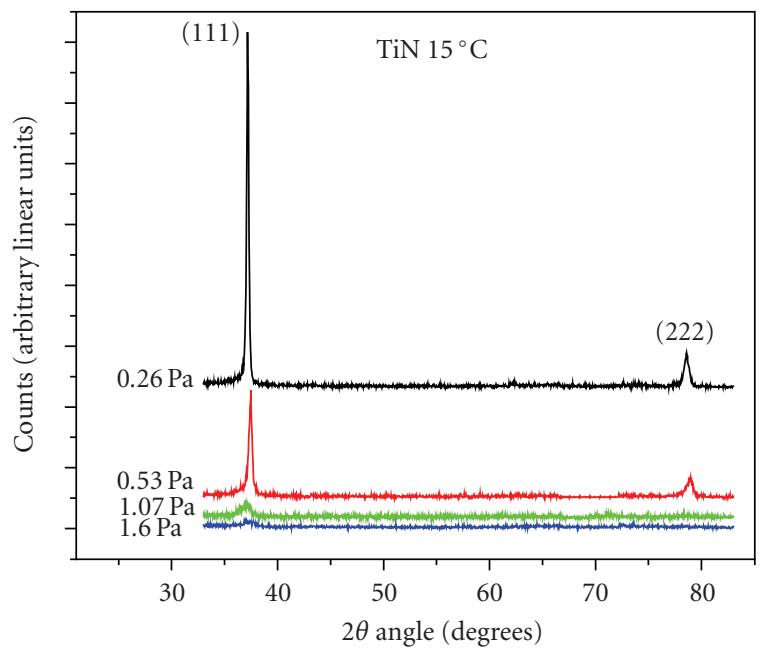

Figure 2: XRD spectra of increasing $P_{P}$ for $T_{S}=15^{\circ} \mathrm{C}$.

then blown dry and inserted into a prevacuum load-lock chamber until reaching a pressure of $10^{-4} \mathrm{~Pa}$. This is followed by insertion into the main preparation chamber where the substrates were pumped on until the preparation chamber reached a base pressure of $10^{-6}-10^{-7} \mathrm{~Pa}$. Further cleaning was achieved by subjecting the substrates to an RF-etching bias (13.52 MHz) of $50 \mathrm{~W}$ for 10 minutes in a pure Ar plasma. The process pressure during etching was $0.53 \mathrm{~Pa}$. This also removes the native oxide layer, ensuring a maximum absence of oxygen within the preparation chamber whose presence could have become an issue, especially during those depositions at elevated $P_{P}$ and $T_{S}$.

Following chamber and substrate conditioning, the substrates were heated to the desired set points via a pair of $1 \mathrm{~kW}$ quartz heating elements that are coupled to a proportional with integral and derivative (PID) controller capable of 


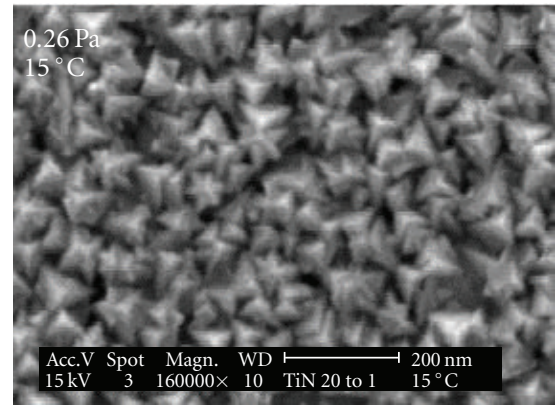

(a)

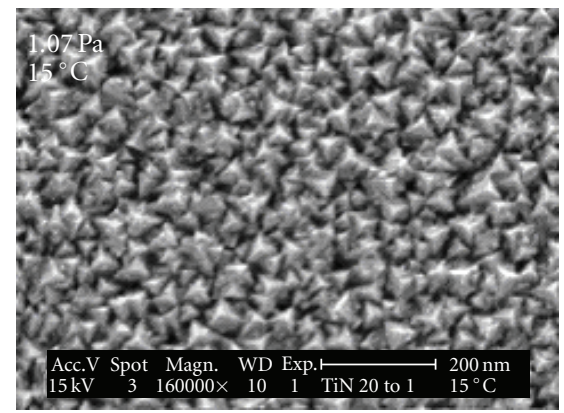

(c)

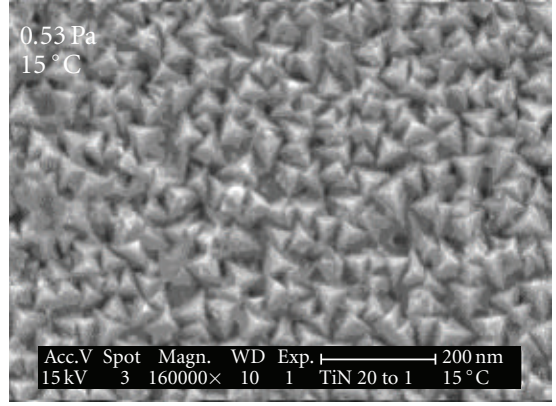

(b)

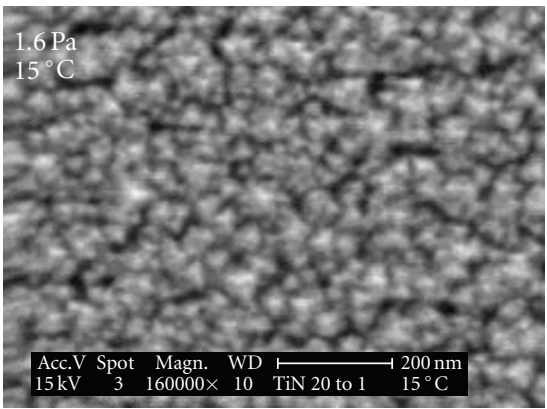

(d)

Figure 3: SEM images of increasing $P_{P}$ at $T_{S}=15^{\circ} \mathrm{C}$ with a) $\left.\left.0.26 \mathrm{~Pa}, \mathrm{~b}\right) 0.53 \mathrm{~Pa}, \mathrm{c}\right) 1.07 \mathrm{~Pa}$ and d) $1.60 \mathrm{~Pa}$.

maintaining set point $\pm 1^{\circ} \mathrm{C}$. $T_{S}$ is monitored throughout by a $k$-type thermocouple which is integrated within a feedback loop with the heating elements and the PID controller. Depositions were performed with $T_{S}$ held constant during the entire processes at set points of $15^{\circ} \mathrm{C}, 200^{\circ} \mathrm{C}, 400^{\circ} \mathrm{C}$, and $600^{\circ} \mathrm{C}$ for each of the $P_{P}$ set points denoted above. Therefore, a total of 16 samples were synthesized by this technique for characterization.

\subsection{Film characterization}

All films were characterized ex situ and at room temperature. Film thicknesses, $t_{f}$, were experimentally confirmed by scanning probe profilometry (SPP) and SEM of their crosssections to be $\sim 500 \mathrm{~nm}$ with no significant variation from film to film. It is important to make this conclusion because it is well known that process pressure and substrate temperature have an effect on the sputter yield and the eventual film thickness [25] and that it has also been shown that the physical properties of TiN films are dependent on film thickness [26].

The surface and cross-sectional morphology were qualitatively ascertained by the implementation of FE-SEM. For cross-sectional characterization, the samples were cleaved in order to expose their underlying microstructure. The instrument used was a Phillips XL30. All samples were imaged with a $15 \mathrm{kV}$ accelerating potential, $50 \mathrm{~nm}$ spot size, $30 \mu \mathrm{m}$ aperture, at a working distance of $10 \mathrm{~mm}$, and all images were gathered by the secondary electron (SE) detector.



Figure 4: XRD spectra of increasing $P_{P}$ for $T_{S}=200^{\circ} \mathrm{C}$.

EDS of all samples was conducted within the Phillips XL30 using the same parameters as above, which produced a projected interaction volume $\sim 500 \mathrm{~nm}^{3}$ allowing for full cross-sectional analysis of the synthesized TiN films. Counts were taken for 90 seconds and the spectra were analyzed with Phillips EDXi software, which allows for background signal removal, peak identification, and peak quantification.

Nondestructive XRD was performed on a Bruker AXS D8 advanced X-ray diffractometer which implements a $\mathrm{Cu}$ 




(a)

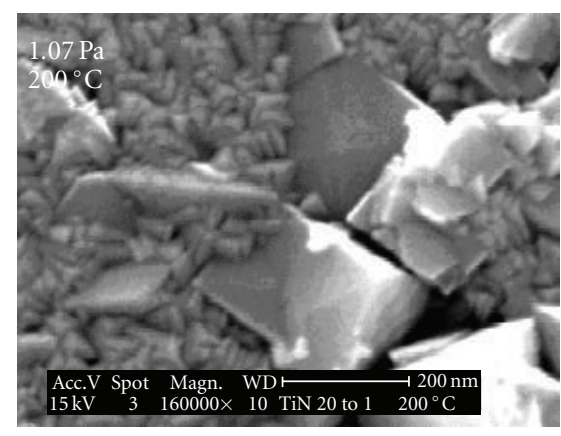

(c)

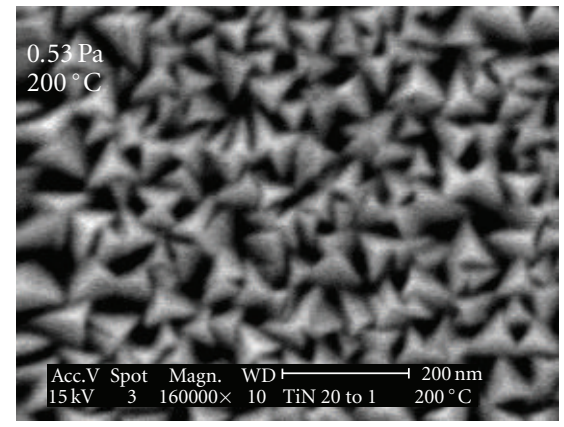

(b)



(d)

FIgure 5: SEM images of increasing $P_{P}$ at $T_{S}=200^{\circ} \mathrm{C}$ with a) $0.26 \mathrm{~Pa}$, b) $\left.0.53 \mathrm{~Pa}, \mathrm{c}\right) 1.07 \mathrm{~Pa}$ and d) $1.60 \mathrm{~Pa}$.

$\mathrm{K} \alpha_{1}(\lambda=1.54058 \AA)$ radiation operated at $40 \mathrm{kV}$ and $40 \mathrm{~mA}$. All scans were taken in continuous mode for a $2 \theta$ range of $33^{\circ}-83^{\circ}$, a step size of $.02^{\circ}$, and time step of 2 seconds. All peaks derived beyond this range are secondary and therefore scans beyond this range are not strictly necessary for crystallographic and/or chemical identification.

\section{RESULTS AND DISCUSSION}

\subsection{Chemical composition}

EDS analysis was implemented to elucidate the stoichiometric composition of the reactively sputtered TiN films and it reveals an increasing nitrogen content within the films with increasing process pressure and substrate temperature as is shown in Figure 1. It is important to note that surface roughness has an effect on EDS results with decreased reliability as the root mean square surface roughness approaches the micron scale. As will be disclosed in Section 3.2, the feature size of the produced films is nanometric and, therefore, localized EDS analysis is minimally affected by the film surface roughness [27]. The film produced at $P_{P}=0.26 \mathrm{~Pa}$ and $T_{S}=15.0^{\circ} \mathrm{C}$ contained 70.4 at. $\%$ nitrogen and the film produced at $P_{P}=1.60 \mathrm{~Pa}$ and $T_{S}=600^{\circ} \mathrm{C}$ had a nitrogen content of 87.0 at.\%, and these were the minimum and maximum nitrogen contents of all of the produced films. This indicates that the combined effects of increasing $P_{P}$ and $T_{S}$ to the upper limit resulted in a 16.6 at.\% increase in the nitrogen content of the TiN films.

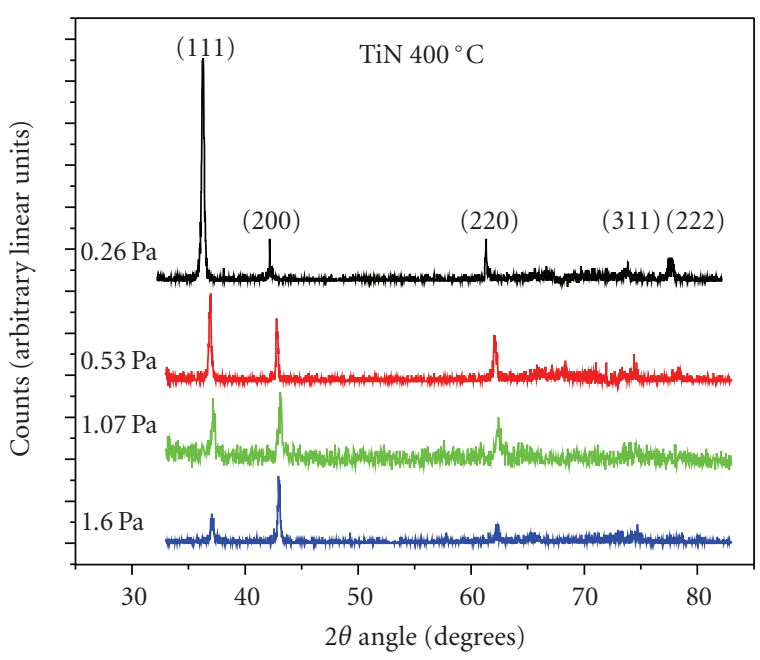

Figure 6: XRD spectra of increasing $P_{P}$ for $T_{S}=400^{\circ} \mathrm{C}$.

The increase in $P_{P}$ from $0.26 \mathrm{~Pa}$ to $1.60 \mathrm{~Pa}$ at a constant $T_{S}$ resulted in a maximum increase in nitrogen content of 10.7 at.\%. This value is obtained by taking the difference of the maximum and minimum nitrogen contents for the denoted process pressure range at each substrate temperature. The average increase in nitrogen content as a function of $P_{P}$ was 9.16 at.\% over the entire temperature range.

Similarly, increasing $T_{S}$ from $15^{\circ} \mathrm{C}$ to $600^{\circ} \mathrm{C}$ with $P_{P}$ held constant at $0.26 \mathrm{~Pa}$ caused the nitrogen content to increase 


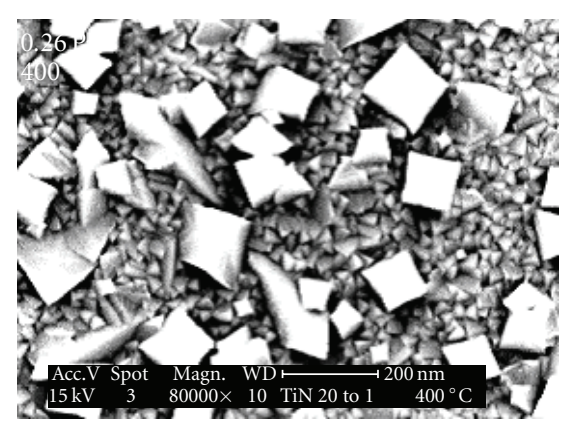

(a)

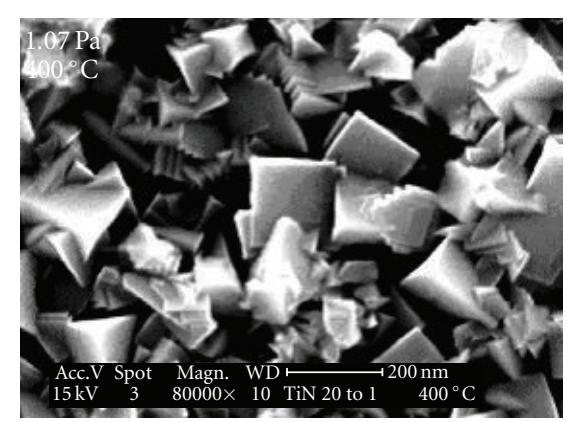

(c)

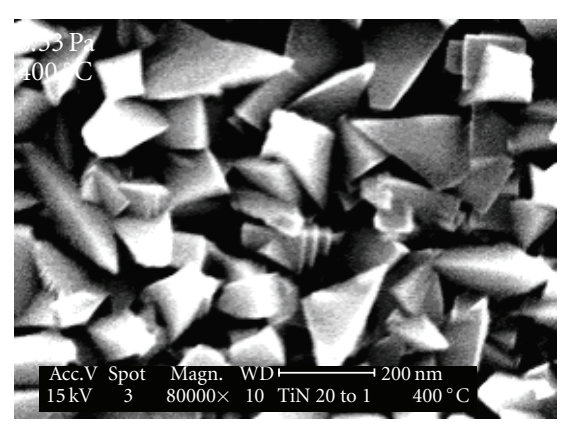

(b)



(d)

Figure 7: SEM images of increasing $P_{P}$ at $T_{S}=400^{\circ} \mathrm{C}$. with a) $0.26 \mathrm{~Pa}$, b) $0.53 \mathrm{~Pa}$, c) $1.07 \mathrm{~Pa}$ and d) $1.60 \mathrm{~Pa}$

from 70.4 at.\% to 81.3 at.\%, a maximum increase of 10.9 at. $\%$. On average, the increased substrate temperature was responsible for a 7.46 at.\% increase in nitrogen content. There appears to be no sign of asymptotic behavior with respect to nitrogen solubility as a function of either $P_{P}$ or $T_{S}$; nonetheless logic indicates that there must exist an upper limit to nitrogen saturation.

\subsection{Surface morphology and preferred orientation: effects of increasing $P_{P}$ and $T_{S}$}

The XRD analysis of the four samples deposited with $T_{S}=$ $15^{\circ} \mathrm{C}$ at each of the defined $P_{P}$ set points indicates that the synthesized material is indeed titanium nitride, namely, the $\delta$-TiN phase (cubic $\mathrm{NaCl}$ structure, $a=4.244 \AA$ ) [28], and that the preferred orientation of the films is along the (111) planes $\left(2 \theta=36.9^{\circ}\right)$ relative to the $(100)$ Si substrates in all cases (Figure 2 ). The smaller peaks at $2 \theta=78.9^{\circ}$ correspond to the secondary (222) planes. Nominally, these peaks are not necessary for crystallographic and/or chemical phase identification, but in this case there is only the emergence of a single primary peak, making it difficult to qualify the data. Hence the presence of the secondary peak in its expected location along with the presence of the primary peak allows for reliable spectrum qualification.

It is also important to notice that the spectra indicate that no other nitrides, oxides, or sillicides of titanium or permutations thereof were synthesized even at increased process pressures and therefore that the films produced are nitrogen-rich TiN indeed.



FIgURE 8: XRD spectra of increasing $P_{P}$ for $T_{S}=600^{\circ} \mathrm{C}$.

The sharpness of the XRD peaks indicates an ordered crystalline structure. This can be qualitatively seen in the SEM images in Figure 3, which indicates that the nanostructured morphology is densely and uniformly packed throughout with an approximate feature size of $75 \mathrm{~nm}$. The intensity of the (111) peaks decreases with increasing pressure and is almost indiscernible for the spectrum corresponding to the $1.60 \mathrm{~Pa}$ film. This indicates that increasing $P_{P}$ at this temperature results in a transition from the (111) orientations to a quasiamorphous phase. 


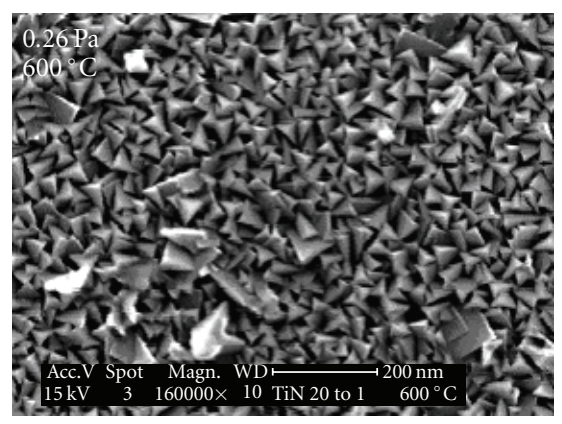

(a)



(c)

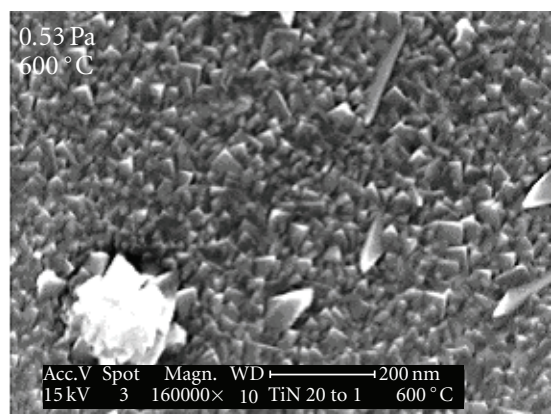

(b)



(d)

FIgure 9: SEM images of increasing $P_{P}$ at $T_{S}=600^{\circ} \mathrm{C}$ with a) $0.26 \mathrm{~Pa}$, b) $\left.0.53 \mathrm{~Pa}, \mathrm{c}\right) 1.07 \mathrm{~Pa}$ and d) $1.60 \mathrm{~Pa}$.
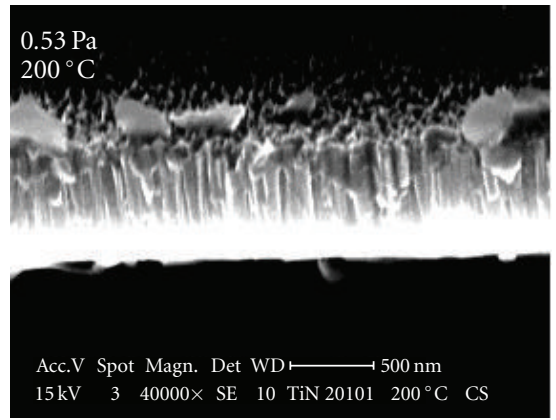

(a)

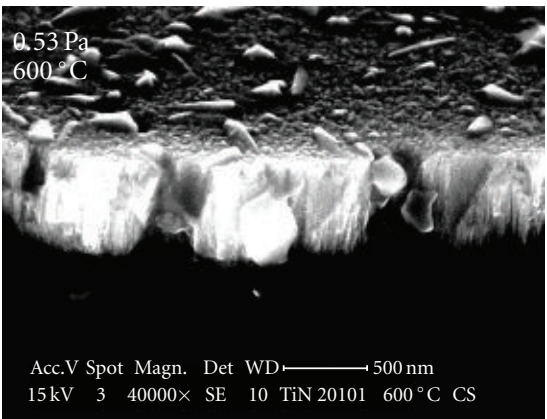

(c)

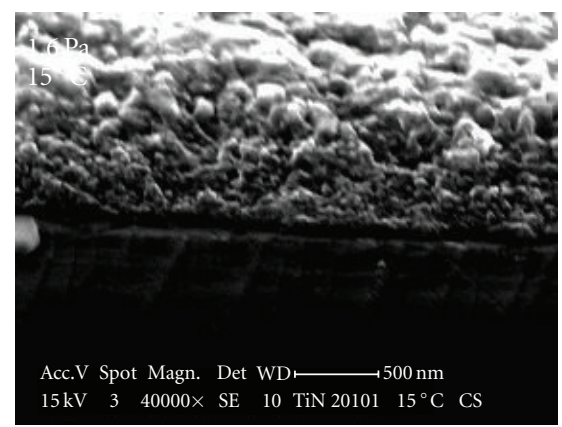

(b)

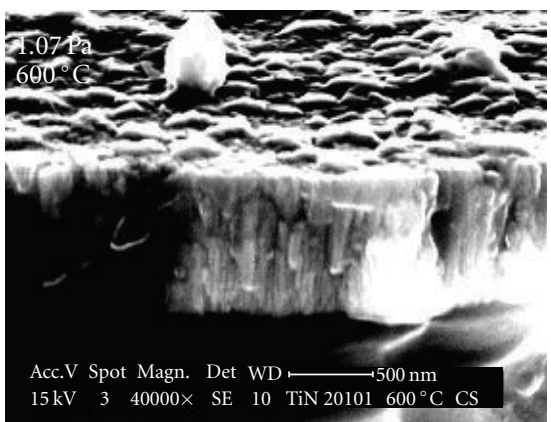

(d)

FIGURE 10: SEM images of typical film cross-sections: (a) pyramidal surface with $P_{P}=0.53 P a$ and $T_{s}=200{ }^{\circ} \mathrm{C}$, (b) amorphous surface with $P_{P}=1.06 \mathrm{~Pa}$ and $T_{s}=15{ }^{\circ} \mathrm{C}$, (c) transitional surface with $P_{P}=0.53 \mathrm{~Pa}$ and $T_{s}=600{ }^{\circ} \mathrm{C}$, and (d) columnar/stratified surface with $P_{P}=1.07 \mathrm{~Pa}$ and $T_{s}=600^{\circ} \mathrm{C}$. 
The SEM images in Figure 3 of these produced films display the variation in their surface morphology. It quickly becomes evident that the films deposited with $0.26 \mathrm{~Pa} \leq P_{P} \leq$ $1.07 \mathrm{~Pa}$ have a pyramidal surface structure with uniformity in the long range and that the surface morphology becomes less distinctive when $P_{P}=1.60 \mathrm{~Pa}$. Based on the information collected by XRD, it is apparent that these pyramids are single crystals of TiN growing with their (111) planes parallel to the substrate. In effect, we are seeing the $\langle 100\rangle$ family planes as the sides of these pyramids. The image of the $1.60 \mathrm{~Pa}$ film supports the conclusion drawn from the XRD spectrum that this film is an amorphous structure with intermittent pyramidal, that is, isolated (111) single crystals.

The overlain spectra of the films produced at a substrate temperature of $200^{\circ} \mathrm{C}$, (Figure 4), indicate that the $\delta$-TiN phase transitions from the (111) orientations to a combination of $(111)$ and $(200)$ orientations $\left(2 \theta=42.8^{\circ}\right)$ as the process pressure is taken to the upper limit. The scanning electron micrographs in Figure 5 for the $0.26 \mathrm{~Pa}$ and $0.53 \mathrm{~Pa}$ films display almost no difference between those films produced at similar pressures but at $15^{\circ} \mathrm{C}$. Again, we see a highly uniform and pyramidal surface structure with no real discerning attributes between one and another. The transition in surface morphology and preferred orientation does not occur at $T_{S}=200^{\circ} \mathrm{C}$ until $P_{P} \geq 1.07 \mathrm{~Pa}$. In this case, the elevated pressures do not cause amorphicivity, instead we see the formation of large $(\sim 200 \mathrm{~nm}) \delta$-TiN (200) single crystals coexisting with the familiar (111) crystals, especially in the film produced at $P_{P}$ $=1.07 \mathrm{~Pa}$. The (200) and (220) planes are referenced and analyzed because the (100) and (110) planes are necessarily forbidden in the $\delta$-TiN XRD spectrum even though they are of the same family because $\delta$-TiN has a cubic $\mathrm{NaCl}$ structure and these planes have mixed Miller indices. Refer to [28] for a complete discussion. As the process pressure is taken to the upper limit, the intensity of the (200) peaks is dominant over the (111) peaks. This is qualitatively confirmed by SEM imaging, whereby the majority of the crystals seen are not the pyramidal (111) crystals but the larger (200) crystals, however, this film is yet completely homogenous.

The films produced at a substrate temperature of $400^{\circ} \mathrm{C}$ exhibit further transition in their preferred orientation and surface morphology. With this set of films, we again see the prominence of the (111) peaks decreasing as the process pressure is elevated. Again, the emergence of the (200) peaks results in these spectra, yet the interesting result here is that the increase in substrate temperature has allowed this transition to occur at a $P_{P}$ of $0.26 \mathrm{~Pa}$, moreover peaks at $2 \theta=61.7^{\circ}$ and $74.4^{\circ}$, corresponding to the (220) and (311) planes, respectively, emerge and increase in intensity with the elevation in the process pressure as shown in Figure 6. Interestingly enough, the SEM images shown in Figure 7 again parallel the XRD results. The surface morphology of the $0.26 \mathrm{~Pa}$ film is unmistakably comprised of pyramidal (111) crystals intermixed with rectangular (200), and parallelogram (220) and (311) crystals. And as the process pressure is increased to $1.60 \mathrm{~Pa}$, the films become less columnar and more stratified with the crystalline planes growing parallel to each other, indicating the increased prevalence of the (200), (220), and (311) orientations over a (111) alignment. The stratified crystals are the (200) crystals growing atop one another.

Again, the feature size is also affected with those films synthesized at elevated set points exhibiting features that are $200-500 \mathrm{~nm}$ in size as opposed to those produced at lower pressures which still contain (111) oriented crystals of approximately $75-100 \mathrm{~nm}$.

Based on the observed trend, it would seem likely that further increasing the substrate temperature would completely eliminate the (111) orientations regardless of the applied process pressure set point, but surprisingly, the films produced at $T_{s}=600^{\circ} \mathrm{C}$ with $P_{P}=0.26 \mathrm{~Pa}$ are still dominantly oriented along the (111) planes, as can be seen in the XRD and SEM results displayed in Figures 8 and 9, respectively. As expected, however, grain coarsening and stratification are activated by increased process pressures as in previous cases. The ultimate conclusion is that the change in surface morphology and preferred orientation are a result of the coupled parametric variations in $P_{P}$ and $T_{S}$.

\subsection{Cross-sectional morphology}

As has been discussed, films produced at lower $P_{P}$ and $T_{S}$ were preferably oriented along the (111) planes and that an increased $P_{P}$ at low $T_{S}$ results in the amorphization of the films as shown in Figures 2 and 3. Moreover, a combined increase in $P_{P}$ and $T_{S}$ results in a transition from the pyramidal (111) orientations to stratified and columnar orientations. Field emission scanning electron microscopy of the as-cleaved cross-sections was implemented to qualify and correlate the cross-sectional microstructure of each typical film type.

The scanning electron micrographs reveal a closely packed and columnar cross-section for those films with a preferred orientation along the (111) planes as shown in Figure 10(a). In essence, the columnar cross-sectional microstructure supports the conclusion that the pyramidal structures are in fact the $\langle 100\rangle$ family of planes and that the film is growing with the (111) planes parallel to the substrate.

Interestingly, the scanning electron micrographs of the cross-sections of the amorphous film reveal a quasiloosely packed underlying microstructure (Figure 10(b)), again correlating as expected with the results derived from XRD and surface SEM.

SEM images of the cross-sections of those films that are transitioning from the (111) preferred orientation to the stratified and columnar orientations as well as those which are fully stratified and columnar are shown in Figures 10(c) and $10(\mathrm{~d})$. The micrographs again reveal a closely packed and columnar cross-section with the absence of pockets or voids. This is in fact the expectation since all of these films are crystalline and are being produced via a PVD route, where films grow from the substrate layer by layer. 


\section{CONCLUSIONS}

Reactive magnetron DC-sputtering of titanium was implemented for the synthesis of TiN thin films. EDS analysis of the as-synthesized films confirmed an overstoichiometric chemical composition with excess nitrogen contents ranging between 70.4 at.\% and 87.0 at.\%. XRD analysis indicates the independent existence of the $\delta$-TiN phase, and that indeed the films produced were a solid solution of the TiN constituents. The effects of increasing $P_{P}$ and $T_{S}$ set points during deposition affected nitrogen solubility within titanium. Increasing $P_{P}$ from $0.26 \mathrm{~Pa}$ to $1.60 \mathrm{~Pa}$ was responsible for a maximum nitrogen content increase of 10.7 at. $\%$ and on average the variation in the $P_{P}$ increased the nitrogen content by 9.16 at.\%. Varying $T_{S}$ between $15.0^{\circ} \mathrm{C}-$ $600^{\circ} \mathrm{C}$ resulted in an increased nitrogen content of up to 10.9 at. $\%$ and an average increase of 7.46 at. $\%$. The nitrogen content in the films increased by 16.6 at.\%, when both $P_{P}$ and $T_{S}$ were taken to their maximum set points.

The surface morphology and preferred orientation were also affected by these parametric variations. Scanning electron microscopy reveals nanometric surface roughness, and that increased $P_{P}$ and $T_{S}$ resulted in a columnar and stratified surface morphology with long-range uniformity. This columnation and stratification are explained by XRD analysis which indicates that the preferred orientation of these films relative to the substrate is along the (200), (220), and (311) planes. Those films produced at lower set points had a pyramidal surface morphology, that is, the preferred orientation is along the (111) planes. Scanning electron microscopy of the as-cleaved cross-sections reveals a closely packed and columnar underlying microstructure for all crystalline films and a loosely packed cross-section for amorphous films.

\section{ACKNOWLEDGMENTS}

This work is sponsored by awards from the University of California, Academic Senate, and the Department of Defense DURIP (ARO/W911NF-07-1-0213).

\section{REFERENCES}

[1] J. M. Molarius, A. S. Korhonen, and E. O. Ristolainen, "TiN phases formed by reactive ion plating," Journal of Vacuum Science \& Technology A, vol. 3, no. 6, pp. 2419-2425, 1985.

[2] W. D. Münz, D. Hoffamn, and K. Hartig, "A high rate sputtering process for the formation of hard friction-reducing TiN coatings on tools," Thin Solid Films, vol. 96, no. 1, pp. 7986, 1982.

[3] R. Buhl, H. K. Pulker, and E. Moll, "TiN coatings on steel," Thin Solid Films, vol. 80, no. 1-3, pp. 265-270, 1981.

[4] R. L. Hatschek, "Coatings: revolution in HSS tools," Special Report 752, American Machinist, March 1983.

[5] S. Niyomsoan, W. Grant, D. L. Olson, and B. Mishra, "Variation of color in titanium and zirconium nitride decorative thin films," Thin Solid Films, vol. 415, no. 1-2, pp. 187-194, 2002.

[6] C. N. Kirchner, K. H. Hallmeier, R. Szargan, T. Raschke, and C. Radehaus, "Contents: electroanalysis 10/2007," Electroanalysis, vol. 19, no. 10, pp. 1019-1021, 2007.
[7] M. Tao, D. Udeshi, S. Agarwal, E. Maldonado, and W. P. Kirk, "Negative Schottky barrier between titanium and n-type $\mathrm{Si}(0$ 0 1) for low-resistance ohmic contacts," Solid-State Electronics, vol. 48, no. 2, pp. 335-338, 2004.

[8] L. A. Cyster, D. M. Grant, K. G. Parker, and T. L. Parker, “The effect of surface chemistry and structure of titanium nitride (TiN) films on primary hippocampal cells," Biomolecular Engineering, vol. 19, no. 2-6, pp. 171-175, 2002.

[9] I. Suni, M. Mäenpää, M. A. Nicolet, and M. Luomajärvi, "Thermal stability of hafnium and titanium nitride diffusion barriers in multilayer contacts to silicon," Journal of the Electrochemical Society, vol. 130, no. 5, pp. 1215-1218, 1983.

[10] Y. L. Jeyachandran, Sa. K. Narayandass, D. Mangalaraj, S. Areva, and J. A. Mielczarski, "Properties of titanium nitride films prepared by direct current magnetron sputtering," Materials Science \& Engineering: A, vol. 445-446, pp. 223-236, 2007.

[11] Y. L. Jeyachandran, S. Venkatachalam, B. Karunagaran, et al., "Bacterial adhesion studies on titanium, titanium nitride and modified hydroxyapatite thin films," Materials Science \& Engineering: C, vol. 27, no. 1, pp. 35-41, 2007.

[12] K. H. Chung, G. T. Liu, J. G. Duh, and J. H. Wang, "Biocompatibility of a titanium-aluminum nitride film coating on a dental alloy," Surface and Coatings Technology, vol. 188-189, pp. 745-749, 2004.

[13] W. Franks, I. Schenker, P. Schmutz, and A. Hierlermann, "Impedance characterization and modeling of electrodes for biomedical applications," IEEE Transactions on Biomedical Engineering, vol. 52, no. 7, pp. 1295-1302, 2005.

[14] Y. Y. Guu, J. F. Lin, and C.-F. Ai, "The tribological characteristics of titanium nitride, titanium carbonitride and titanium carbide coatings," Thin Solid Films, vol. 302, no. 1-2, pp. 193200, 1997.

[15] J. Bonse, P. Rudolph, J. Krüger, S. Baudach, and W. Kautek, "Femtosecond pulse laser processing of TiN on silicon," Applied Surface Science, vol. 154-155, pp. 659-663, 2000.

[16] J. Bonse, H. Sturm, D. Schmidt, and W. Kautek, "Chemical, morphological and accumulation phenomena in ultrashortpulse laser ablation of TiN in air," Applied Physics A, vol. 71, no. 6, pp. 657-665, 2000.

[17] A. Intemann, H. Koemer, and F. Koch, "Film Properties of CVD titanium nitride deposited with organometallic precursors at low pressure using inert gases, ammonia, or remote activation," Journal of the Electrochemical Society, vol. 140, no. 11, pp. 3215-3222, 1993.

[18] C. Carney and D. Durham, "Optimization of hardness by the control of microwave power in TiN thin film deposited by electron cyclotron resonance assisted sputtering in a nitrogen plasma," Journal of Vacuum Science \& Technology A, vol. 17, no. 5, p. 2535, 1999.

[19] H. Köstenbauer, G. A. Fontalvo, M. Kapp, J. Keckes, and C. Mitterer, "Annealing of intrinsic stresses in sputtered TiN films: the role of thickness-dependent gradients of point defect density," Surface and Coatings Technology, vol. 201, no. 8, pp. 4777-4780, 2007.

[20] J.-H. Huang, K.-W. Lau, and G.-P. Yu, "Effect of nitrogen flow rate on structure and properties of nanocrystalline TiN thin films produced by unbalanced magnetron sputtering," Surface and Coatings Technology, vol. 191, no. 1, pp. 17-24, 2005.

[21] S.-S. Yang, Y.-R. Lin, and S.-T. Wu, "Room temperature epitaxial growth of TiN on SiC," Surface and Coatings Technology, vol. 201, no. 9-11, pp. 4850-4853, 2007.

[22] S. H. Ahn, J. H. Hong, J. G. Kim, and J. G. Han, "Effect of microstructure on corrosion behavior of TiN hard coatings 
produced by a modified two-grid attachment magnetron sputtering process," Thin Solid Films, vol. 515, no. 17, pp. 6878-6883, 2007.

[23] E. O. Ristolainen, J. M. Molarius, A. S. Korhonen, and V. K. Lindroos, "A study of nitrogen-rich titanium and zirconium nitride films," Journal of Vacuum Science \& Technology A, vol. 5, no. 4, pp. 2184-2189, 1987.

[24] H. A. Wriedt and J. L. Murray, "The N-Ti (nitrogen-titanum) system," Bulletin of Alloy Phase Diagrams, vol. 8, no. 4, pp. 378388, 1987.

[25] M. Ohring, The Materials Science of Thin Films, Academic Press, San Diego, Calif, USA, 1992.

[26] L. Combadiere and J. Machet, "Reactive magnetron sputtering deposition of TiN films. I. Influence of the substrate temperature on structure, composition and morphology of the films," Surface and Coatings Technology, vol. 88, no. 1-3, pp. 17-27, 1997.

[27] L.-M. Peng, S. L. Dudarev, and M. J. Whelan, High-Energy Electron Diffraction and Microscopy, Oxford University Press, New York, NY, USA, 2004.

[28] B. D. Cullity, Elements of X-Ray Diffraction, Addison-Wesley, Menio Park, Calif, USA, 2nd edition, 1978. 



The Scientific World Journal

Submit your manuscripts at

http://www.hindawi.com

\section{World Journal}

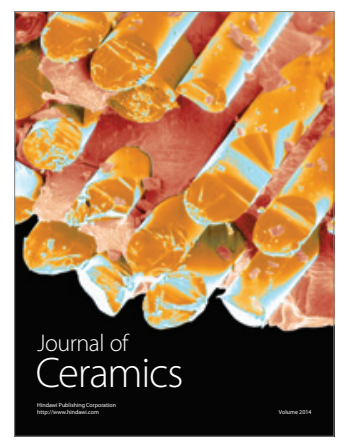

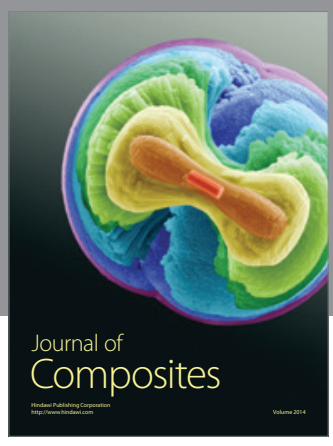
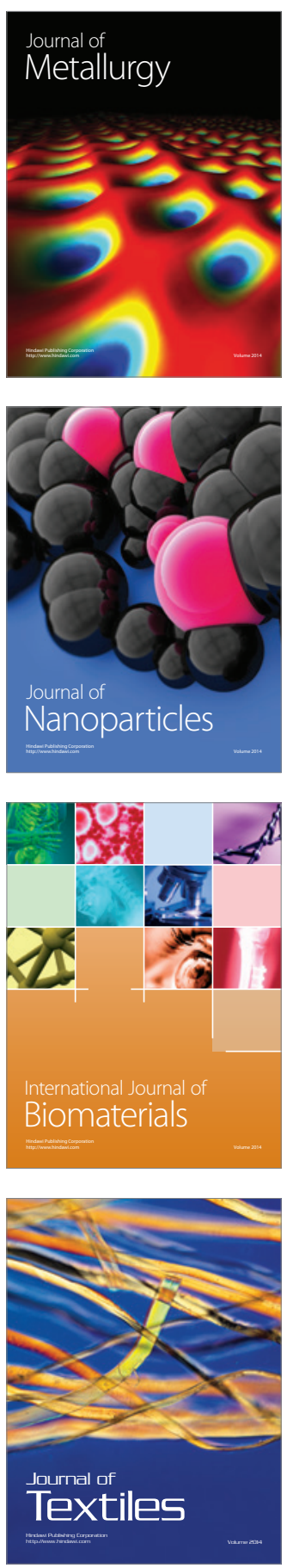